Iogical security than it has ever occupied before. Far, then, from joining the "contention " of my critic in seeking to depose natural selection as a theory of the genesis of adaptive structures and instincts, I have expressly sought to fortify that theory as a "mechanical" explanation of these phenomena. Whether or not I have been successful I must leave others to judge, after they have done me the justice to read ny original paper. But, be this as it may, the ambiguity of that paper must indeed be extraordinary, if it leads any one to suppose that my argument is precisely the opposite of what it is intended to be.

Geanies, Ross-shire, August 16

George J. Romanes

\section{Meteorology and Colliery Explosions}

The catastrophe at Woodend Colliery on Friday last again directs attention to the connection generally believed to exist between explosions of fire-damp and atmospheric changes. The real nature of this connection is but little, if at all, understood. From time to time observations have been taken with the view of throwing some light on the subject, but as the observations in one mine were discussed without reference to what may have been occurring in other districts, the results have not added much to our knowledge. Meteorology, however, is now sufficiently advanced to permit the adoption of another and more satisfactory method of dealing with the question.

The idea so long prevalent that certain fixed points on the barometric scale indicated certain kinds of weather has now been discarded, the examination of synchronous weather charts showing conclusively that the weather changes are not so much dependent upon the height of the barometer at any one place as upon the relations existing between readings over a tract of country; the direction in which the highest and lowest readings lie, and the difference of pressure (the barometric gradient) between neighbouring places - these form the basis of our modern weather knowledge. Nothing of this kind has hitherto been attempted when dealing with observations from collieries. If the presence of gas in mines is in any way regulated by changes of atmospheric pressure, it would be well to see if, like the weather, it is distributed in areas, and whether in these areas again some localities would have more gas than others, de pendent more upon the distribution of pressure than upon local readings. With the object of discovering some law or laws governing the presence of gas, I appeal to colliery official; in every coal-field in Great Britain and Ireland to supply me with the few observations detailed below for a period of four months -from September I to December 3I, the best part of the year for such work.

The Meteorological Office Weather Charts issued daily (Sundays included) at $8 \mathrm{a} . \mathrm{m}$. and $6 \mathrm{p} . \mathrm{m}$. show the distribution of pressure, winds, temperature, and weather. To these I propose adding the information supplied from mines at the same hours. Those who cannot arrange for two observations daily, to give preference to the morning set. The gas observation being the most important, I would be glad if precise information can be given. Absolute uniformity cannot be expected, but I would suggest that, where possible, a disused gallery favourable to the object in view should be usəd, one where the changes in the quantity of gas can be stated in yards or feet, thus turning the gallery into a gas barometer somewhat similar to the one at Seaham Colliery after the explosion of a few years ago. Those who have not the facilities for such measurements can still give valuable data if they do no more than note the increase or decrease of gas as "slight," "moderate," or "great." The appended specimen of the form for recording the observations

$$
\text { Form for Recording Observations }
$$

$$
\text { ................ Colliery, near ............... }
$$

\begin{tabular}{|c|c|c|c|c|c|c|c|}
\hline \multirow{2}{*}{$\begin{array}{c}\text { Date, } \\
\text { September } \\
\text { 1886 }\end{array}$} & \multicolumn{2}{|c|}{$\begin{array}{l}\text { Top of shaft, } \\
\text {..... feet above } \\
\text { sea-level }\end{array}$} & \multicolumn{3}{|c|}{$\begin{array}{c}\text { In underground workings, } \\
\ldots . . . \text { yards from shaft } \\
\text {...... feet below pit-bank }\end{array}$} & \multirow{2}{*}{$\begin{array}{l}\text { Gas in } \\
\text { gallery, } \\
\text { yards }\end{array}$} & \multirow{2}{*}{ Remarks } \\
\hline & $\begin{array}{l}\text { Tempe- } \\
\text { rature } \\
\text { in the } \\
\text { shade }\end{array}$ & Weather & $\begin{array}{l}\text { Baro- } \\
\text { meter }\end{array}$ & $\begin{array}{l}\text { Tempe- } \\
\text { rature }\end{array}$ & $\begin{array}{c}\text { Quan- } \\
\text { tityof ain } \\
\text { passing }\end{array}$ & & \\
\hline $\begin{array}{r}\text { Ist, } 8 \text { a.m. } \\
6 \text { p.m. } \\
\text { 2nd, } 8 \text { a.m. } \\
6 \text { p.m. }\end{array}$ & & & & & & & \\
\hline
\end{tabular}

has columns for the air-temperature in the shade at the pit-bank, and the weather; while underground, in addition to the gas record, the reading of a barometer and thermometer, and quantity of air passing at a fixed point some distance in the workings ; also, remarks on the variations of the gas and ventilation at other than the regular hours. A sheet of close-ruled foolscap, arranged as indicated, will contain the data for one month, and, as soon as filled up, should be forwarded to me at the Meteorological Office, London, S.W. On the back of the first return particulars are required of the geographical position of the mine, the name and address of the manager, whether the barometer is a mercurial or an anersid, together with the readings of the same at the pit-bank at $8 \mathrm{a} . \mathrm{m}$. daily for a week before taking it underground, and describing the plan adopted in measuring the gas. It must be understood that I am undertaking the discussion as my own work, for which the Meteorological Council is not responsible.

August I6

HY. HARRIES

\section{Railway Weather Signals}

WITH reference to the notice given in NATURE, vol. xxxiv. p. 347 , of the ingenious plan adopted by the Norwegian Meteorological Institute for clisseminating its weather reports, it may not be known to all of your readers that a similar system of signals has been in use for some time on the railroads in Ohio, Pennsylvania, and Canada. The day signals there consist of sheetiron disks about three feet in diameter, and are displayed on the side of baggage-cars. The signals are shaped like the sun, a crescent, or a star, and differ in colour, being red or blue. The red colour refers to the temperature, and the blue to the state of the weather, as rainfall or snow. This system of signals was first brought into practical operation by Prof. T. C. Mendenhall, Chief of the Ohio Meteorological Bureau.

A system of night-signals for railways is also under trial in Pennsylvania: they are in the form of rockets or an exploding cartridge, which, when fired, may be seen from six to ten miles.

\section{August 17}

\section{Tornaria and Actinotrocha of the British Coasts}

THREE species of Balanoglossus are known to occur on the shores of North. West Europe. Balcrioglossus kupfferi was taken by Willemoes Suhm at Helleback, in the Sound, that is, on the coast of Zealand (Zeit. f. zuiss. Zool. vol, xxi. r871); Balanoglossus salmonews, Giard, and B. rebinii occur, according to $\mathrm{Mr}$. Bateson's last paper in the Owarterly Fournal of Microscopical Science, at Concarneau, in Finistère, and I believe also at the Channel Islands. But no Balanoglossus has yet been found on the shores of Britain. It will therefore be of some interest to British naturalists to learn that in August I884 I obtained in the townet a larva which seemed to possess the distinctive characters of Tornaria. I had not leisure at the time to study the specimen with much attention, but I made a hurried sketch of it, which shows the presence of two parallel longitudinal bands of cilia anteriorly, and a single transverse band posteriorly. A.t the posterior end is a conical prot berance resembling the adhesive organ described by Bateson in his creeping larva. The position of the mouth was not ascertained, but was probably between the two anterior bands of cilia. The water vessel and tuft of cilia at the apex of the præoral lobe were not observed. This larva may not have been Tornaria, but I think it really was that form ; and naturalists who are spending an autumn holiday at the seaside would probably, if they undertook the search, succeed in finding Balanoglossus in the lirtoral sands, and its larva in the shore waters.

Phorenis is also at present, I believe, excluded from the British littoral fauna, but is certainly present on our shores, though no adult specimens have been taken. I took large numbers of Actinotrocha in the tow-net, close to the shore, in September 1883 , a little to the north of the mouth of the Cromarty Firth If I am mistaken in supposing that arlult Phorenis and Balanoglossus have never been found on the coast of Britain, I shall be glad to be corrected.

J. T. CunNingham

\section{Mock Suns}

As I observe the omission from my letter on the pathelia or mock suns of last month (p. 313) of the diagram which was 
intended to describe the real phenomena, may I ask you to allow me a few lines of space for the following :-

The real sun was surrounded at a short distance by a halo or rainbow circle of great beanty, with a mock sun of the same apparent magnitude and brightness on the right and left; and partially formed suns above and below the ring: all of them being slightly opalescent. From the two perfected suns proceeded cones of intense light, about 3 diameters of the sun in length, and with their apices pointing east and west. These were rather more opalescent than the mock suns from which they seemed to originate. A second rainbow ring at a considerable distance vutside of these extended to the zenith. The period of greatest beauty and brightness, when they were as rich in colouring as a real rainbow, lasted about 5 minutes. I was able to watch the whole of the phenomena from a little after 4 to nearly 6 o'clock.

Jasper Road, Upper Norwood

\section{PHYSIOLOGICAL SELECTION: AN ADDI- TIONAL SUGGESTION ON THE ORIGIN OF SPECIES ${ }^{1}$}

III.

ARGUMENT from the Prevention of Intercrossing.-

This argument is the same from whatever cause the prevention of intercrossing may arise. Where intercrossing is prevented by geographical barriers or by migration, it is more easy to prove the evolution of new species as a consequence than it is when intercrossing is prevented by physiological barriers; for in the latter case the older and the newer forms will probably continue to occupy the same area, and then there will be no independent evidence to show that the severance between them was due to the prevention of intercrossing. Nevertheless, all the evidence I have of the large part that geographical barriers have played in the evolution of species by preventing intercrossing with parent forms goes to show the probable importance of physiological barriers when acting in the same way. Hence it will be better to postpone this line of argument in favour of physiological selection until the appearance of my next paper, where I shall hope to show, from evidence furnished by the geographical distribution of species, how predominant a part the prevention of intercrossing has played in the evolution of species. Here, therefore, I will merely remark that wherever intercrossing with parent forms is prevented, in the proportion that it is prevented a better opportunity is given to natural selection for seizing upon any beneficial variations that may happen to arise. On this account physiological selection probably lends important aid to natural selection, thus becoming indirectly instrumental in the evolution of useful as well as of useless structures.

There is also another respect in which these two kinds of selection probably co-operate. For Mr. Darwin shows that "it would be clearly advantageous to two varieties, or incipient species, if they could be kept from blending, on the same principle that, when man is selecting at the same time two varieties, it is necessary that he should keep them separate." But he proceeds to show that this advantage cannot be conferred by natural selection, and hence that the sterility which is so generally characteristic of species cannot be attributed to this agency. We have, however, just seen that this sterility is in all likelihood due to physiological selection; and therefore, if it be true, as Mr. Darwin thought, that "it would profit an incipient species if it were rendered in some slight degree sterile with its parent form," physiological selection and natural selection may mutually assist one another. For, although the benefit of this sterility could not have been initially conferred by natural selection, yet when it once arises from an independent variation in the reproductive system, there is no reason why it should not forthwith be favoured by natural selection, just as is the case with advantageous variations in general.

T Abstract of a Paper read before the Linnean Society on May 6, by George J. Romanes, M.A., LL.D., F.R.S. \&c. Continued from p. 340 .
Feeling how grave a difficulty was presented to his theory of the origin of species by the general sterility of species, Mr. Darwin was extremely anxious to find some way in which natural selection might be seen to have brought about this result. Had it occurred to him that this result was probably nothing more than the necessary expression of a particular kind of variation on the part of the reproductive system, I cannot doubt that he would have felt the theory of natural selection to have been relieved of one of its greatest disabilities.

Argument from the Inutility of Specific Differences.After what has already been said on this subject, I will here only deal with one question, namely, Why is it that apparently useless structures occur in such profusion among species, in much less profusion among genera, and scarcely at all among families, orders, and classes? It may be answered that the points wherein species differ from species are usually points of smaller detail than those which distinguish genera, families, \&c., and thus may well actually be as a rule less useful, although still not absolutely useless : natural selection, it may be urged, is better able than is the naturalist to diagnose utility. But here again we have a most unwarranted appeal to the argument from ignorance ; whereas, according to my view, it is quite intelligible that when a varietal form is differentiated from its parent form by the bar of sterility, isolation, or migration, any little meaningless peculiarities of structure (or of instinct ${ }^{1}$ ) should at first be allowed to arise, but should eventually be eliminated as so much surplusage in the struggle for existence, by economy of growth, or even by independent variation when undirected by natural selection. A greater or less time would in different cases be required to effect this reduction, and thus we can understand why they are sometimes allowed to persist into genera, but rarely into families.

Again, if apparently useless specific characters (whether these be new structures or modifications of old ones, slight changes in form, colour, and so forth) are thus regarded as really useless, we should expect that they ought to be of a kind which do not impose much physiological tax upon the organism, since otherwise natural selection would not have allowed them to become so much as specific characters. Well, I have applied this test, and find it is a most general rule that specific characters the utility of which cannot be perceived are such as do not impose any considerable demand for nourishment: either on account of their small size or of their organically inexpensive material, they do not impose much tax upon the organism. Now it is obvious that there can be no connection between utility as disguised and smallness of size or inexpensiveness of material; while it is no less obvious that there is a close connection between these things and a real inutility.

Lastly, our domesticated varieties "occasionally exhibit well-marked and more or less constant characters of a useless kind. Here there can scarcely be any question about the genuineness of the inutility, seeing that the characters have arisen only under domestication, or in the absence of any struggle for existence. Yet these structures are sometimes of the most curious and complex morphology--even more so than innumerable apparently useless structures in the case of natural species."

Argument from Divergence of Character.-Any theory of the origin of species in the way of descent must be prepared with an answer to the question, Why have species multiplied? Why have they not simply become transmuted in linear series instead of ramifying into branches? This question Mr. Darwin seeks to answer

I For instances of useless instincts see Mr. Darwin's posthumous essay published in my "Mental Evolution in Animals." It is suggestive in the present connection that, just like useless structures, useless instincts, so far as I can find, only occur in species and genera: never in families, orders, or classes.

For a good instance of this see "Variation of Plants and Animals under Domestication," vol. i. pp. $7^{8-79}$. 